\title{
Percutaneous Osteosynthesis with Headless Cannulated Screws in the Treatment of Metacarpal and Proximal and Middle Phalanxes Fractures of the Hand
}

\section{Osteosíntesis percutánea con tornillos canulados en el tratamiento de fracturas de metacarpianos y falanges de dedos largos de la}

\section{mano}

\author{
Oscar Carrera Casal ${ }^{1}$ María Jesús Rivera Vegas ${ }^{1}$ Miguel Eugenio Estefanía Díez ${ }^{1}$ Pilar García Cano ${ }^{1}$ \\ Javier Antonio Maya Gonzalez ${ }^{1}$ Endika Nevado Sanchez ${ }^{1}$
}

${ }^{1}$ Service of Plastic Surgery, Esthetics and Restoration, Hospital Universitario de Burgos, Burgos, Spain

Rev Iberam Cir Mano 2018;46:117-125.
Address for correspondence Oscar Carrera Casal, MD, Complejo Asistencial Universitario de Burgos, Burgos, Spain (e-mail: oscarcarreracasal@gmail.com).

\section{Abstract \\ Keywords \\ - metacarpal fractures \\ - phalangeal fractures \\ - cannulated screw}

\section{Resumen}

Introduction There is a high incidence of hand fractures, and a high percentage of them require surgical treatment. The functional result depends, to a large extent, on the technique used. The use of retrograde intramedullary screws allows for early mobilization and minimal dissection of soft tissues. The objective of the present study is to analyze the clinical results and complications with this type of osteosynthesis.

Methods A total of 96 fractures in 81 patients were analyzed. There were 62 metacarpal fractures, $60 \%$ of which involved the $5^{\text {th }}$ finger, $29 \%$ involved the $4^{\text {th }}, 5 \%$ involved the $3^{\text {rd }}$, and $6 \%$ involved the $2^{\text {nd }}$ finger. There were 34 fractures of the phalanxes, 27 of which (79.5\%) involved the proximal phalanx, and $20.5 \%$ involved the middle phalanx. The range of active mobility, the time spent at work, and intraoperative complications were assessed.

Results The average active mobility obtained was $260^{\circ}\left(230-270^{\circ}\right)$. Patients resumed their normal activity within an average time of 5 weeks (between 3 and 32 weeks). There was a $6 \%$ rate of intraoperative complications and a $13 \%$ rate of postoperative complications in the metacarpals, and an $8 \%$ rate of intraoperative complications and $11 \%$ of postoperative complications in the phalanxes.

Conclusion The use of cannulated screws is a safe and effective option for the treatment of different types of fractures, obtaining a good range of mobility, early reintegration, and with an acceptable number of complications.

Introducción Las fracturas de la mano tienen una alta incidencia y en un alto porcentaje se deben tratar de forma quirúrgica. Su resultado funcional depende en gran medida del tipo de técnica empleada. El uso de tornillos intramedulares retrógrados con permite una movilización precoz y una mínima disección de partes blandas. received

August 6, 2018

accepted

October 10, 2018
DOI https://doi.org/

10.1055/s-0038-1676080. ISSN 1698-8396.
Copyright $\odot 2018$ Thieme Revinter Publicações Ltda, Rio de Janeiro, Brazil

License terms

(c) (1) $\ominus$ (\$) 
Palabras clave

- fracturas mecacarpianas

- fracturas falángicas

- tornillo canulado
El objetivo de este trabajo es analizar los resultados clínicos y complicaciones con este tipo de osteosíntesis.

Material y Método Se han analizado 96 fracturas de 81 pacientes. Las fracturas metacarpianas fuero 62 , de las cuales un $60 \%$ corresponden al $5^{\circ}$ dedo, el $29 \%$ al $4^{\circ}$, un $5 \%$ y $6 \%$ al $3^{\circ}$ y $2^{\circ}$, respectivamente. Las fracturas de las falanges fueron 34,27 de las cuales el $79,5 \%$ correspondieron a la falange proximal y el $20,5 \%$ a la falange media. Se valoró el rango de movilidad activo, el tiempo de incorporación laboral y las complicaciones intraoperatorias.

Resultados La movilidad activa obtenida fue de $260^{\circ}$ media $\left(230-270^{\circ}\right)$. Los pacientes se reincorporaron a su actividad habitual con un tiempo medio de 5 semanas (entre 3 y 32 semanas). Existió un 6\% de complicaciones intraoperatorias y un 13\% de complicaciones postoperatorias en los metacarpianos y un $8 \%$ de complicaciones intraoperatorias y un $11 \%$ de complicaciones postoperatorias en las falanges.

Conclusión La utilización de tornillos canulados es una opción segura y eficaz, para el tratamiento de los diferentes tipos de fracturas. Obteniendo un buen rango de movilidad, una reincorporación precoz y con un número de complicaciones aceptable.

\section{Introduction}

There is a high incidence of hand fractures, which correspond to the second most common fracture after the distal radius. ${ }^{1}$ They have a great impact on the daily activity of the patients, who are usually young people of working age. The treatment depends on factors associated with both the fracture and the patient; the fracture site must be stabilized, restoring grip capacity and allowing good early mobilization.

Treatment with immobilization is indicated when the fracture is clinically stable after reduction. ${ }^{2}$ The advantages of fixation with Kirschner wires are that they are relatively easy to place and extract, and also cheap. However, they do not allow an adequate understanding of the fracture, requiring prolonged immobilization, with the risk of joint stiffness. ${ }^{3}$ The plates and screws provide adequate fixation, which allows early mobilization, avoiding stiffness. Internal fixation involves soft tissue dissection, which consequently causes scar tissue to appear on the osteosynthesis plate and on the focus of the fracture, facilitating the tenodesis effect. ${ }^{4}$

To achieve adequate fixation of the fracture, and following the experience of other authors ${ }^{5-7}$ we use retrograde intramedullary cannulated screws in the treatment of fractures of the metacarpals and of the proximal and middle phalanxes. This technique provides rigid fixation and compression of the focus, with minimal soft tissue involvement.

The aim of the present study is to present our experience and the difficulties we have had in our learning curve with this technique.

\section{Methods}

We have studied the evolution of patients treated with retrograde intramedullary screws in the Plastic, Aesthetic and Reconstructive Surgery Department at the Hospital Universitario de Burgos who underwent surgery for fractures of the metacarpals and proximal and middle phalanxes from December 2013 to December 2017.

A total of 96 fractures in 81 patients (67 men and 14 women) were included.

The criteria for this technique were unstable fractures, fractures in multiple fingers, or patients requiring immediate mobilization, performing an individual assessment of each case.

Surgery was performed by different surgeons, in a regulated manner, using the screws available in our hospital: AcutrakAcumed standard, micro and mini, and Tarma screws.

Of the total 81 patients, $5 \%$ received general anesthesia, $33 \%$ with axillary block, and $62 \%$ received local anesthesia without ischemia (-Fig. 1).

Presurgical antibiotic prophylaxis was prescribed with cefazolin $2 \mathrm{~g}$ in a single dose, in cases of closed fractures, and treatment with co-amoxiclav, in cases of open fractures, pre and postoperatively.

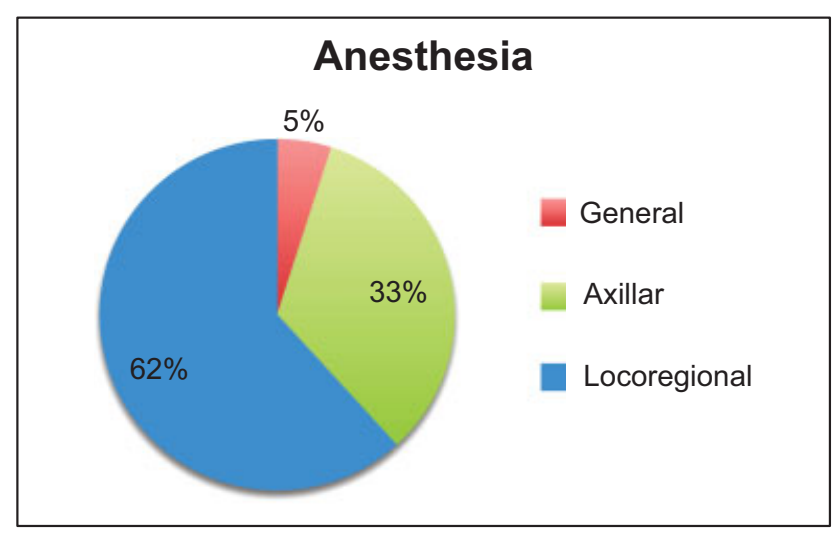

Fig. 1 Percentage of distribution of operations according to the anesthetic technique performed. 
Table 1 Screw size in relation to the affected metacarpal

\begin{tabular}{|c|c|}
\hline \multicolumn{2}{|c|}{ Metacarpals } \\
\hline Finger & Total \\
\hline \multicolumn{2}{|l|}{4 mm } \\
\hline 2 & 4 \\
\hline 3 & 3 \\
\hline 4 & 4 \\
\hline 5 & 31 \\
\hline \multicolumn{2}{|c|}{$3.5 \mathrm{~mm}$} \\
\hline 4 & 13 \\
\hline 5 & 6 \\
\hline \multicolumn{2}{|c|}{$2.5 \mathrm{~mm}$} \\
\hline 4 & 1 \\
\hline
\end{tabular}

\section{Metacarpals}

A total of 62 fractures were treated in 53 patients with an average age of 36.2 years old ( 47 men and 6 women), with 8 patients with fractures in more than one metacarpal ( 7 patients with fractures in 2 metacarpals, and 1 patient with fractures in 3 metacarpals).

Sixty percent of the metacarpal fractures involved the $5^{\text {th }}$ finger, $29 \%$ involved the $4^{\text {th }}, 5 \%$ involved the $3^{\text {rd }}$, and $6 \%$ involved the $2^{\text {nd }}$ finger.

Most of the fractures were transverse and short oblique (92\%), except for $8 \%$, which were long oblique fractures.

The follow-up lasted between 6 months and 4 years after surgery, with a mean follow-up of 12 months.

We used screws with a diameter of $4 \mathrm{~mm}$ in $71 \%$ of cases, of $3.5 \mathrm{~mm}$ in $27 \%$, and of $2.5 \mathrm{~mm}$ in $2 \%$ (-Table 1 ). Five cases (8\%) involved open fractures, with different degrees of soft tissue involvement.

\section{Proximal and Middle Phalanxes (- Table 2)}

A total of 28 patients with 34 phalangeal fractures (20 men and 8 women) were interviewed, with an average age of 46 years old. Of these, four patients presented with fractures of two phalanxes, and one presented with fractures of four phalanxes of the same hand.

Of the 34 fractures, 27 were proximal phalangeal fractures (79.5\%), and 7 were middle phalangeal fractures (20.5\%).

One fracture was long oblique, another was a pathological fracture due to an enchondroma, and in two cases a corrective osteotomy of a previously orthopedically treated fracture was performed.

Follow-up lasted between 8 months and 4 years, with a mean follow-up of 18 months.

Acumed screws with a diameter of $4 \mathrm{~mm}$ were used in $8 \%$ of the patients, of $3.5 \mathrm{~mm}$ in $40 \%$ of the patients, of 2.5 in $35 \%$ of the patients, and $3 \mathrm{~mm}$ Tarma ${ }^{\circledR}$ AutoFIX ${ }^{\mathrm{TM}}$ screws (Industrias Electromédicas Tarma S.A., Madrid, Spain) were used in $17 \%$ of the patients (-Table 2 ). Six patients presented with open fractures $(17.6 \%)$, and there were 3 cases of intraarticular involvement.
Table 2 Screw size in relation to the affected phalanx

\begin{tabular}{|c|c|}
\hline \multicolumn{2}{|l|}{ Phalanxes } \\
\hline Finger/Phalanx & Total \\
\hline \multicolumn{2}{|l|}{4 mm } \\
\hline 3/P1 & 2 \\
\hline 4/P1 & 1 \\
\hline \multicolumn{2}{|l|}{$3.5 \mathrm{~mm}$} \\
\hline 2/P1 & 3 \\
\hline 3/P1 & 1 \\
\hline 4/P1 & 2 \\
\hline 5/P1 & 7 \\
\hline $2 / P 2$ & 1 \\
\hline 3/P2 & 1 \\
\hline \multicolumn{2}{|l|}{$3 \mathrm{~mm}$} \\
\hline 2/P1 & 1 \\
\hline 4/P1 & 1 \\
\hline $5 / P 1$ & 1 \\
\hline $2 / P 2$ & 1 \\
\hline 4/P2 & 2 \\
\hline \multicolumn{2}{|l|}{$2.5 \mathrm{~mm}$} \\
\hline 4/P1 & 1 \\
\hline 5/P1 & 7 \\
\hline 3/P2 & 1 \\
\hline 4/P2 & 1 \\
\hline
\end{tabular}

Abbreviations: P, phalanx.

\section{Surgical Technique}

Closed reduction of the fracture and full joint flexion are performed under the chosen anesthetic technique and radioscopic control (-Fig. 2).

\section{Metacarpals}

Due to the bone geometry, after the metacarpophalangeal flexion, the articular location of the screw inlet is in the most dorsal $3^{\text {rd }}$, with a reduced involvement of the arc of movement of the joint involved. ${ }^{8}$

The skin and subcutaneous cellular tissue are cut open, exposing the tendon of the extensor muscle, so that when the joint is flexed, the cap or transverse lamina moves over the proximal phalanx.

\section{Proximal and Middle Phalanxes}

Due to the bone geometry and after the maximum possible flexion of the proximal interphalangeal joint (PIJ) and of the distal interphalangeal joint (DIJ), the Kirschner wire is placed) in the intercondylar position after a minimal soft tissue incision.

Anatomical studies show that the longitudinal tendon incision in the PIJ is $0.5 \mathrm{~cm}$ away from the insertion of the central band, avoiding the development of boutonniere deformity. In the DIJ, the tendon incision is separated from 

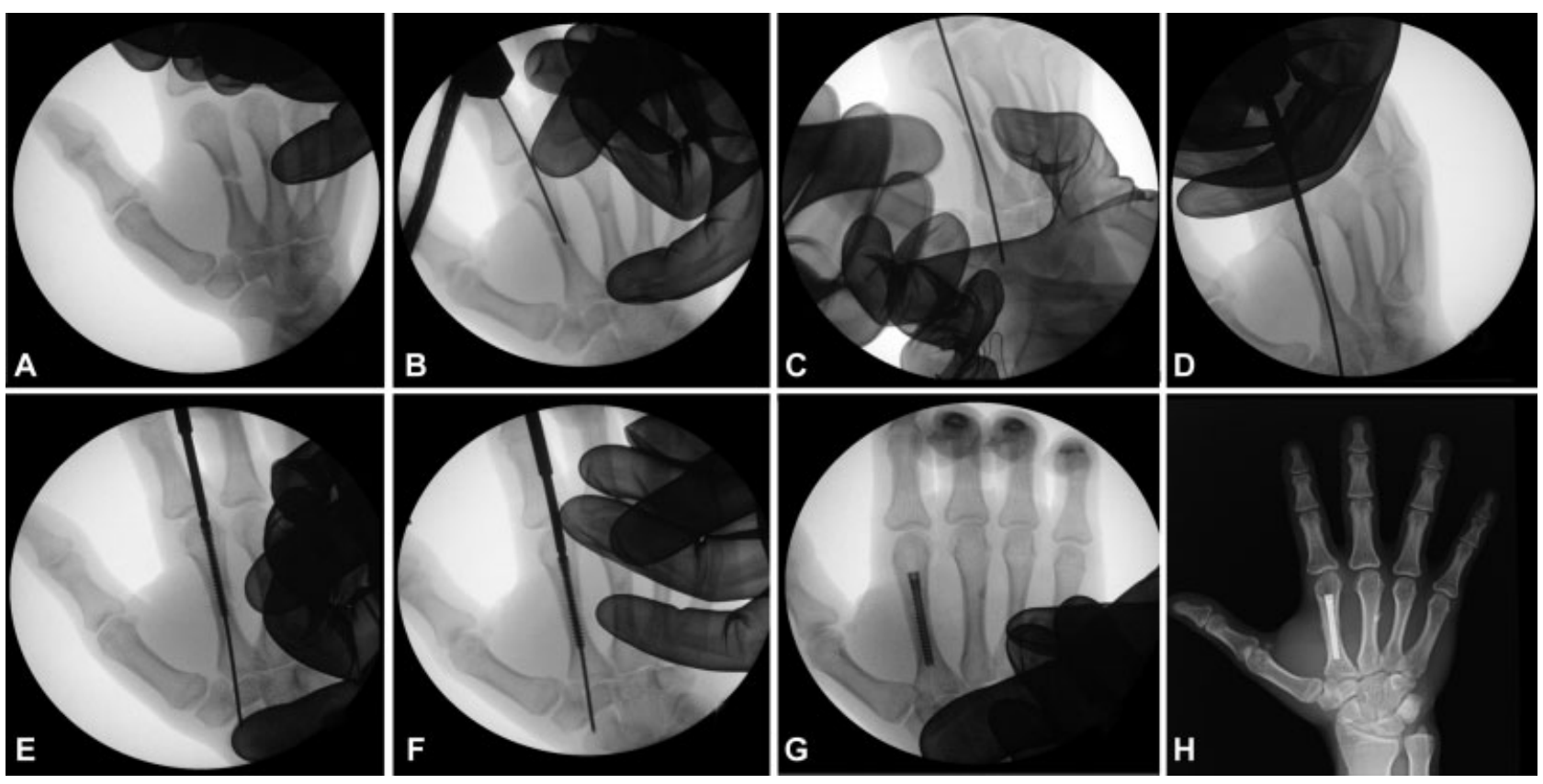

Fig. 2 Percutaneous osteosynthesis technique with cannulated screws. A: Closed reduction. B and C: Intramedullary K-wire placement. D: Channel broaching. E and F: Insertion of intramedullary screw. G: Intraoperative management. H: Result at 2 months.

the terminal insertion of the extensor apparatus, avoiding the development of mallet finger ${ }^{8}$

The placement of the Kirschner wire is the most important step. Central placement in the medullary cavity is essential to avoid cortical fractures and to fix the two portions of the bone fracture. A canal broach is then performed using the wire as a guide.

After measuring the medullary cavity width, ${ }^{9}$ the most appropriate screw is selected, in width and length, to allow the fixation of the portions of the fracture, fitting between the bone cortexes without producing bulging or fracture.

It is essential that the heads of the screws are buried in the metaphysis, avoiding joint alterations that would cause difficulties such as postoperative stiffness or pain.

It is not necessary to close the longitudinal lesion in the extensor apparatus because it is minimal and skin closure is performed with a stitch.

\section{Postoperative}

The majority of the operations were performed as outpatient surgery. Immobilization took place for an average of 7 days, subsequently starting active mobilization, except in cases involving soft tissue injuries.

The range of total active mobility of the affected finger was assessed as a fundamental item, using a goniometer to measure the range of each digital joint.

The time to return to normal activity was measured from the time the patients were operated until they started working, if in employment, or resumed their preinjury activities, if the patients were non-workers.

Intraoperative complications such as cortical fracture, loss of fracture fixation, inadequate placement or rupture of the implant, and postoperative complications including skin, tendon, bone, joint or infection problems were also evaluated.

\section{Results}

\section{Metacarpals}

Patients operated on achieved an average active mobility of $260^{\circ}\left(230-270^{\circ}\right)$. The patients resumed their normal activity with an average time of 5 weeks (3-32 weeks) (-Figs. 3, 4, 5).

The limb was immobilized for an average of 5 days, with a longer period for open fractures, which also required a longer recovery time.

\section{Intraoperative Complications}

- Diaphysis rupture: In one case, there was a burst diaphysis on insertion of the screw. Once visualized, the complication was resolved with the placement of a narrower screw. As it was a greenstick fracture, a perfect alignment and fixation of the fracture was achieved.

- Lack of fracture fixation: In one case, there was a lack of fracture fixation as the loops did not fit between the cortex, therefore a "window" had to be opened in the cortex in order to extract the screw.

- Inadequate placement of the screw: Two patients affected with a $5^{\text {th }}$ metacarpal neck fracture required removal of the screw due to an inadequate reduction of the focus.

Intraoperative complications affected $6 \%$ of the cases.

\section{Postoperative Complications}

- Cutaneous: In one patient, in whom three screws were placed in two metacarpals, we found hypertrophic scars at the screw entry points. The patient had no associated symptoms.

- Tendinous: No extensor tendon injury or functional deficit were observed. One patient operated on for a $5^{\text {th }}$ metacarpal 

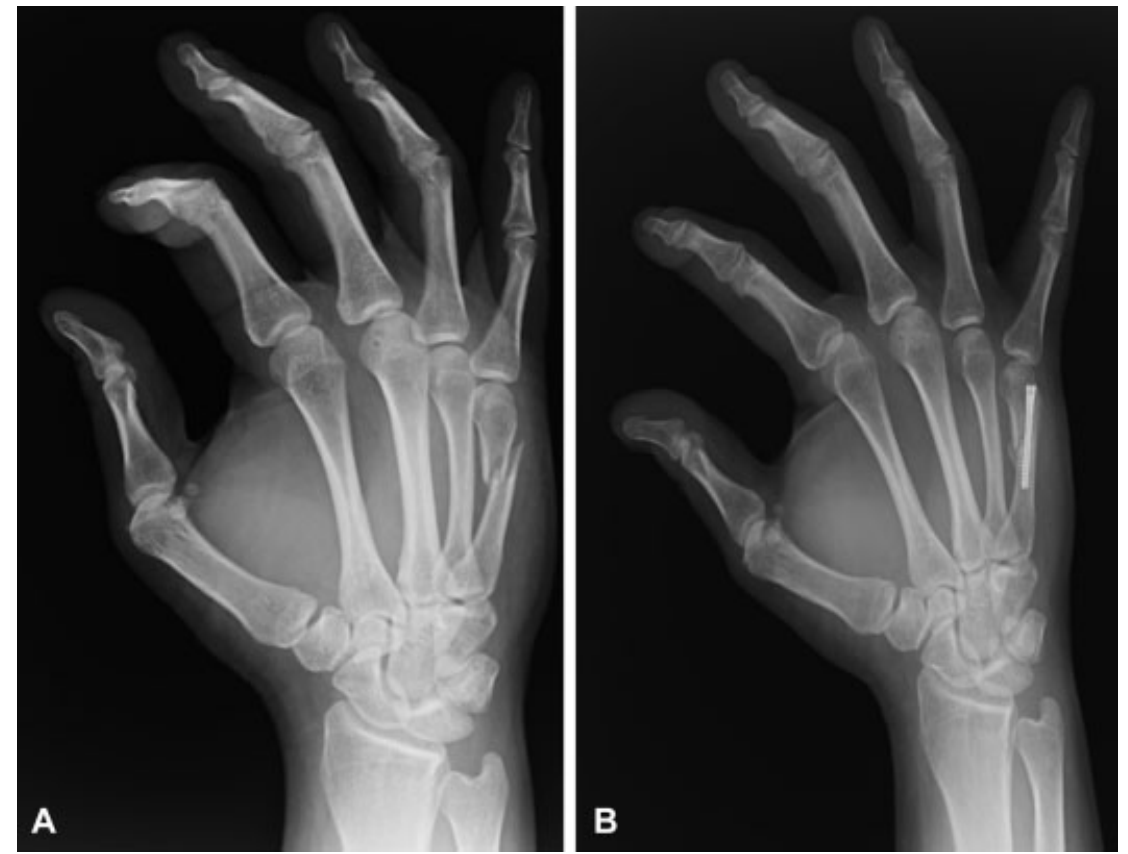

Fig. 3 A: 33-year-old patient with $5^{\text {th }}$ metacarpal fracture. B: Result at 3 months.
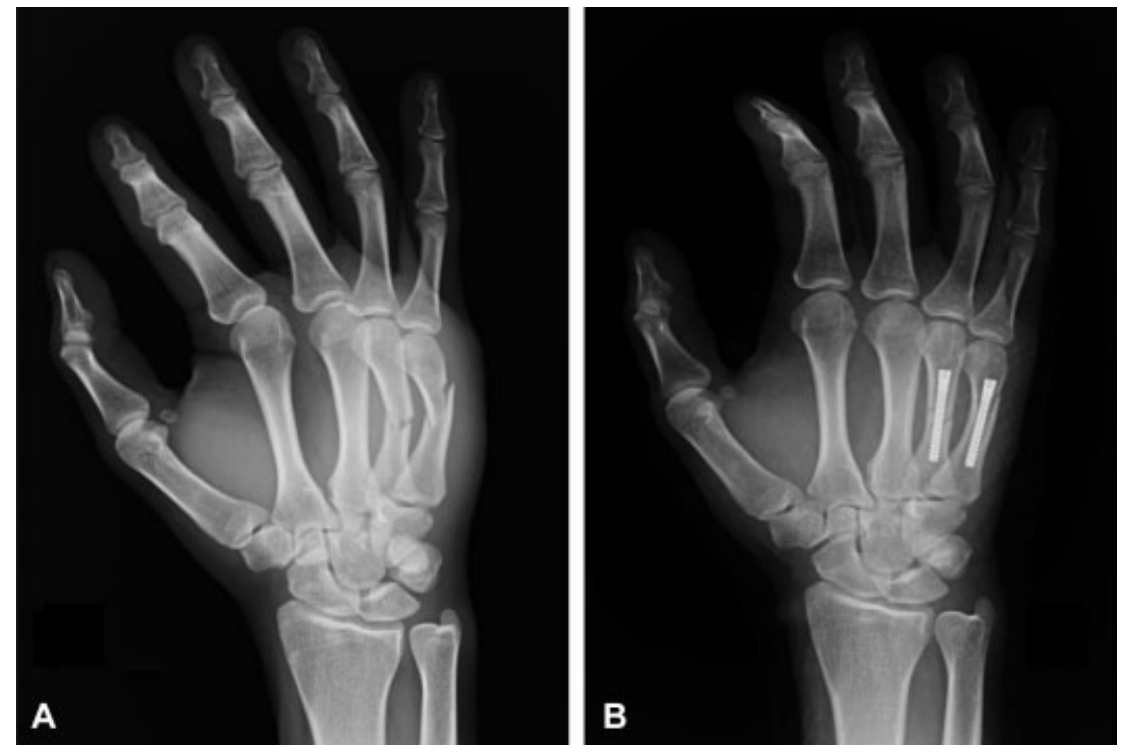

Fig. 4 A: 22-year-old patient with $4^{\text {th }}$ and $5^{\text {th }}$ metacarpal fracture. B: Result after 1 year.

bone fracture presented with trigger finger 2 months after treatment of the fracture with a steroid injection.

- Bone: There were no pseudoarthrosis or delays in consolidation. In long oblique fractures, there was a shortening due to fracture sliding (maximum $4 \mathrm{~mm}$ ) without functional repercussion.

- Joint: No joint rigidity was noted in any of the evaluated cases, without flexion or extension deficit.

- Signs of joint arthrosis: So far, we have not observed any signs or symptoms of joint arthrosis.

- Infections: At the time of data collection from the present study, we have not found any infections associated with the implant.
- Reflex Sympathetic Dystrophy (RSD): Two patients with severe soft tissue involvement presented with RSD, which was resolved with medical and rehabilitation treatment.

In total, $13 \%$ of the patients suffered some form of mild postoperative complication, with no functional repercussion at the end.

\section{Proximal and Middle Phalanx}

The phalangeal fracture cases achieved an average active mobilization range of $240^{\circ}\left(165^{\circ}-270^{\circ}\right)$, resuming their normal activity between 5 and 60 weeks after surgery, with an average time of 9 weeks. The lower ranges of mobility are associated with open fractures (-Figs. 6, 7, 8). 

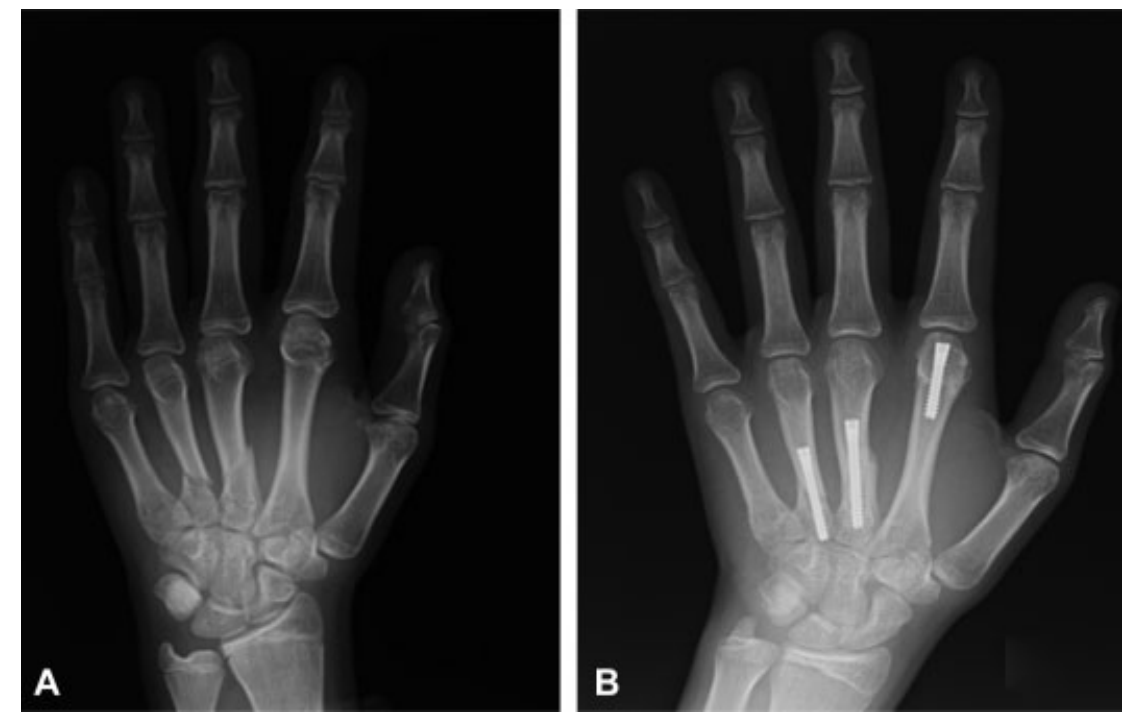

Fig. 5 15-year-old patient with $2^{\text {nd }}, 3^{\text {rd }}$ and $4^{\text {th }}$ metacarpal fracture. Result at 6 months.
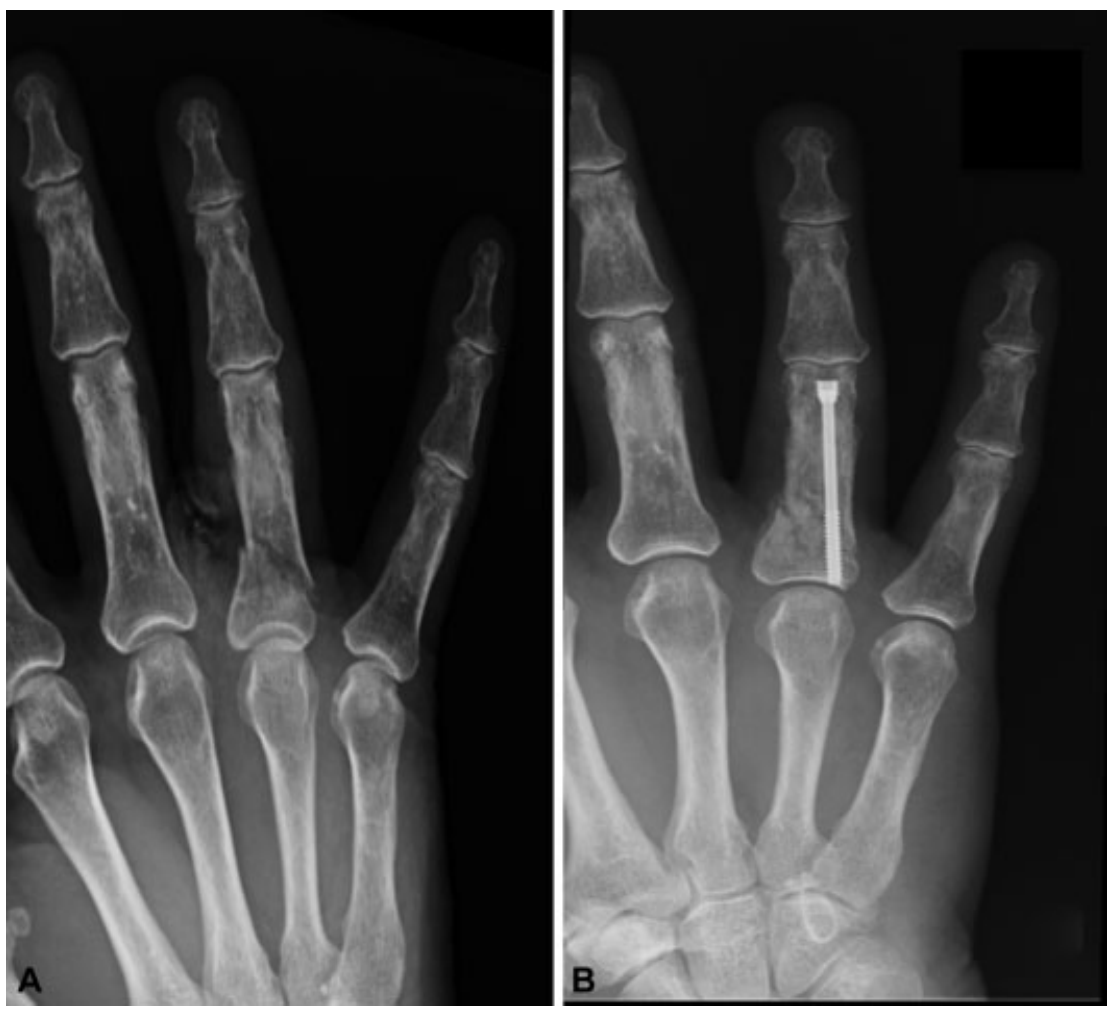

Fig. 6 83-year-old patient with fracture of the proximal phalanx of the $4^{\text {th }}$ finger. Result at 3 months.

Eighty percent of the patients required rehabilitation treatment to achieve full mobilization. The mean period of immobilization in these patients was of 10 days (0-30 days), with a longer period in patients with soft tissue involvement.

\section{Intraoperative Complications}

- Diaphyseal fracture: In one case, diaphyseal fracture occurred with bulging of the cortex, without functional repercussion.

- Loss of fracture fixation: We have not had any case in the present series.
- Implant thread rupture during placement: After the insertion of the screw, without having passed the fracture line, the thread ruptured, which prevented the surgery from progressing and required that the surgical technique be changed. This patient is not included in the present series.

- Poor implant placement: In one case, dorsal protrusion of the screw was observed at the PIJ, associated with an infectious condition treated with antibiotic therapy. After the consolidation of the fracture, the screw was extracted with favorable progress. 

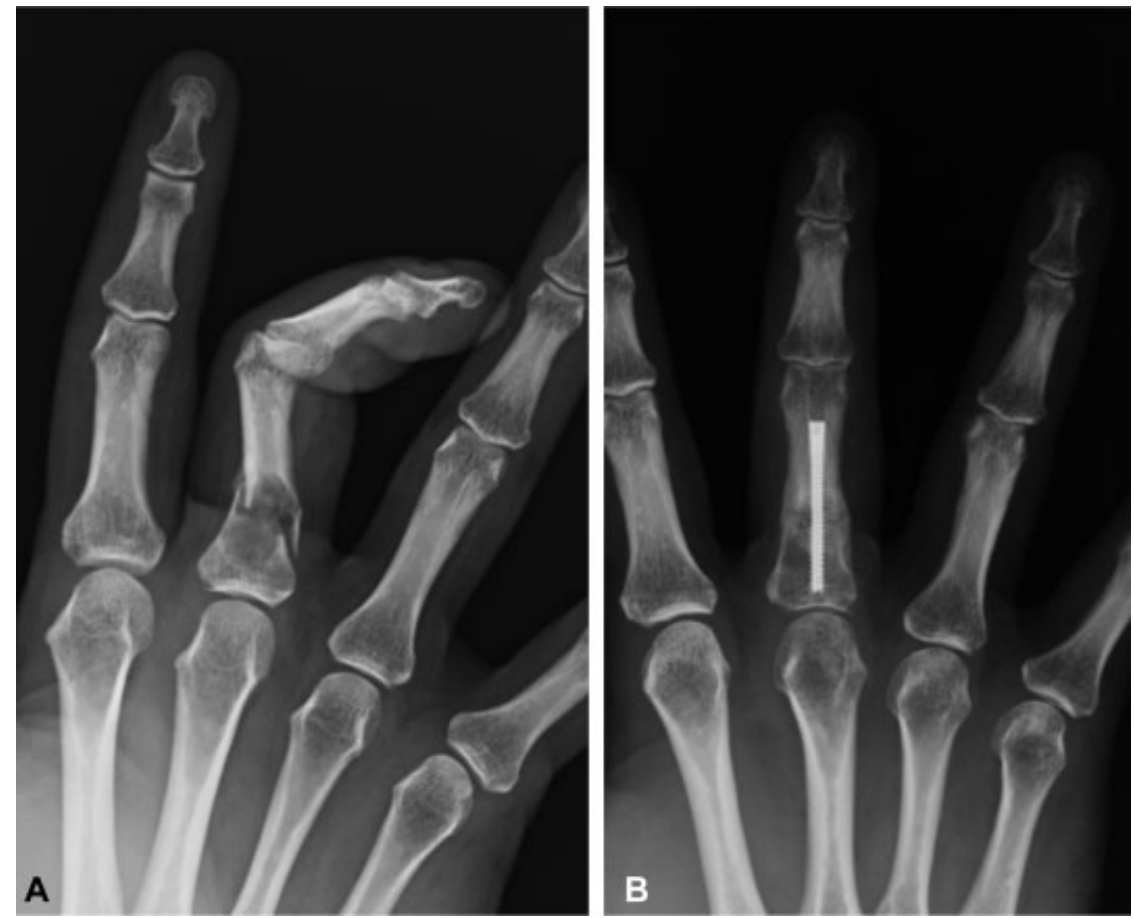

Fig. 7 A: 36-year-old patient with pathologic proximal phalanx enchondroma fracture of the $4^{\text {th }}$ finger. B: Osteosynthesis after curettage of the lesion and cancellous bone graft at 2 months.
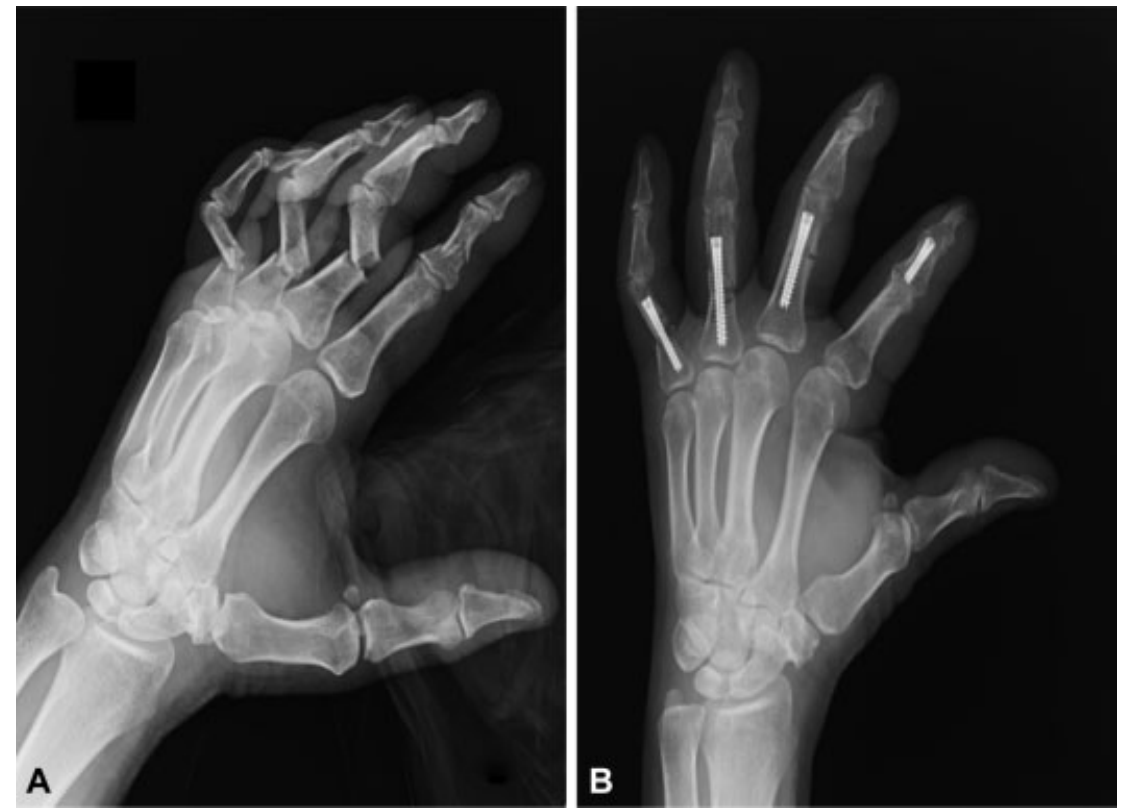

Fig. 8 A: 68-year-old patient with middle phalanx fracture of the $2^{\text {nd }}$ finger and proximal phalanx fracture of the $3^{\text {rd }}, 4^{\text {th }}$ and $5^{\text {th }}$ fingers. Result at 3 months.

In total, $8 \%$ of the cases involved intraoperative complications.

\section{Postoperative Complications}

- Cutaneous: No alterations were observed in the cutaneous scar.

- Tendinous: In one case of corrective osteotomy of the proximal phalanx, tenoarthrolysis of the extensor apparatus was required with final mobility of $220^{\circ}$ and ade- quate functionality. No tendon ruptures were found in the present series. A PIJ extension deficit between 5 and $10^{\circ}$ with complete flexion occurred in $20 \%$ of the patients operated on for proximal phalangeal fracture. In the DIJ, the extension deficit of up to $15^{\circ}$ reaches $27 \%$.

- Bone: There was no delay in consolidation, pseudoarthrosis, or shortening. There was a case of malrotation with adequate functional compensation in a proximal phalanx fracture-dislocation. 


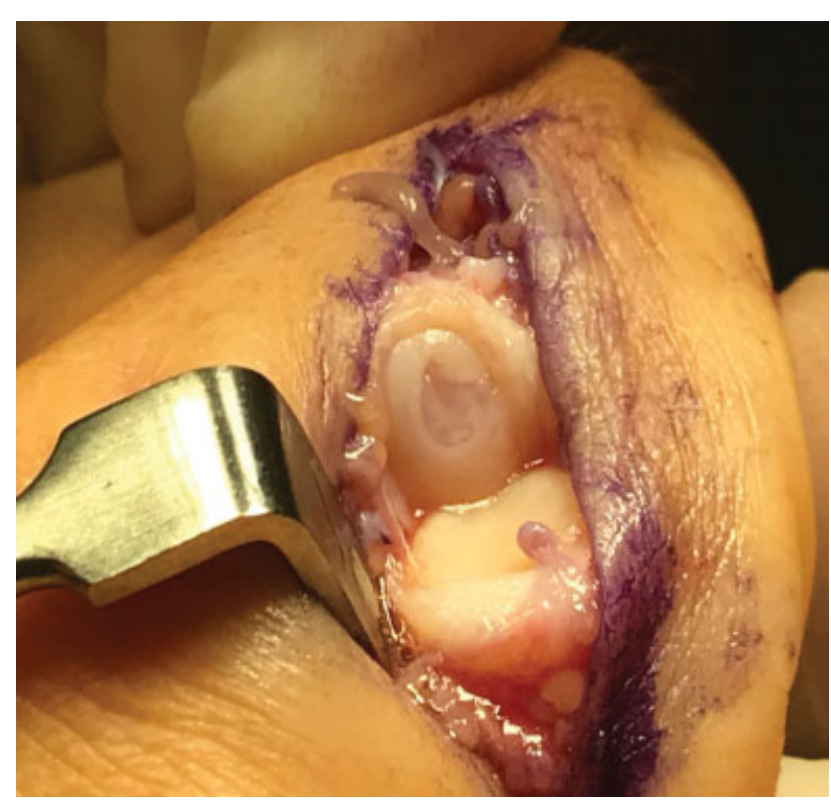

Fig. 9 Cartilage defect of the $2^{\text {nd }}$ metacarpal articular surface in a patient previously operated on with percutaneous osteosynthesis. Courtesy of Dr. Del Cerro

- Joint: One patient presented joint stiffness in an open fracture with associated tendon rupture.

- Signs of joint arthrosis: Not found in our series at the time of assessment.

- Infection: One patient presented with an infectious condition after the screw placement and was treated with antibiotic therapy. After observing radiological signs of consolidation, it was decided to remove the screw with a favorable final result.

- Reflex sympathetic dystrophy: There were no cases of RSD in the studied series.

In total, $11 \%$ of the patients suffered postoperative complications, with moderate impairment in final functionality. The mild loss of extension without functional repercussion mentioned above is not included in this percentage.

\section{Discussion}

We present our experience in the treatment of metacarpal and of proximal and middle phalanx fractures, by placing intramedullary screws.

The treatment of hand fractures is challenging. Our goal is to achieve early mobilization and limit complications. There are different techniques in the treatment of fractures, with advantages and disadvantages.

Kirschner wire presents complications, and although complications have been documented in $18 \%$ of the cases, there were no permanent effects in most of them. ${ }^{10}$ Among the most significant, we consider the loss of adequate fixation that prevents early rehabilitation, among others. ${ }^{11,12}$

Although treatment with plates and screws provides excellent stability, complications may arise. Implantation of low-profile plates provided improved benefits, but they continue to cause scarring that includes the soft tissues due to their thinness on the dorsal bone surface, causing a deficit of mobility, among other complications. ${ }^{13-15}$

Stiffness after hand fractures is often difficult to treat. The best treatment is prevention through early mobilization and control of edema and pain.

According to Gaston et al, ${ }^{16}$ the ideal surgery for unstable fractures of the proximal phalanx in athletes should be minimally invasive and associated with implants with greater resistance, allowing mobility and early return to sports. This concept applied to the treatment of any type of hand fracture, conditions that meet the technique evaluated in the present study.

With intramedullary screws, the cutaneous lesion is limited to the point of insertion, avoiding the damage associated with an open technique and wide dissection. In our series, we only have one case of hypertrophic scars in a young patient, possibly due to broach abrasion. In addition, these closed synthesis techniques avoid tendinous scar injuries and greatly limit secondary inflammation of this structure associated with the synthesis material, which can cause tendon rupture. ${ }^{17}$ With the technique that uses intramedullary screws, whether they are placed by retrograde or anterograde technique, stable fixation occurs with minimum soft tissue damage, explained by the fact that there is no contact between the tendon and the screw. The retrograde placement method we used requires tenotomy of the extensor apparatus, and anatomical placement does not affect normal functioning, nor does it cause tendon rupture. ${ }^{9}$ This is supported by the absence of tendon damage in our series in patients with closed fractures.

To date, we have found no purely articular clinical involvement secondary to cartilaginous injury. This is limited to the dorsal articular part, which is not the support area in gripping by hand (-Fig. 9).

The intraoperative complications that we have presented in the results chapter cannot be attributed to the technique, but rather to an inadequate execution of the technique, which was a result of the learning curve in the first cases treated.

Our clinical and functional results are similar to those found in several series published in recent years, showing satisfactory results with this type of treatment..$^{5-7,18,19}$ The surgical treatment of the metacarpal has been very effective, with results close to $100 \%$ mobility.

The functional results and the evolution of patients with phalangeal fractures are satisfactory, although somewhat lower compared with metacarpal fractures. This is expected when comparing this type of fracture, the age and soft tissue involvement of the patient, which are factors in poorer prognosis. In our series, the mean age is higher ( 36.2 versus 46 years old), as well as the percentage of open fractures ( $8 \%$ versus $17.6 \%$ ) in phalangeal fractures compared with metacarpal fractures. ${ }^{20}$

By not requiring an open approach, we have dispensed with the use of ischemia, which allows us to operate on closed fracture patients using local anesthesia, thus reducing waiting and admission times. At the same time, we verified during the surgery the adequate reduction with active mobilization from the patient. To avoid the spontaneously exit of the wire after broaching, we pass a cortex proximal to the fracture. 
We immobilized closed fractures for the first few days, with a view to using antalgics, allowing subsequent mobilization, although with the accumulated experience, the tendency is to reduce it to a minimum. We show patients the exercises that they should carry out independently, as a result of which most people manage to resume their normal activities between 1 and 2 months postoperatively. The most complex cases are referred to the rehabilitation service.

Indications for the technique are closed fractures with transverse or short oblique line, in which an adequate closed reduction with external maneuvers can be achieved. One limitation in the use of the technique is in long oblique fractures, in which achieving an adequate reduction during screwing is difficult due to compression, almost always leading to some form of shortening. Meunier et $\mathrm{al}^{21}$ found that $2 \mathrm{~mm}$ of shortening produces a minimum power loss of $8 \%$, and that $10 \mathrm{~mm}$ of shortening causes a power loss of $45 \%$ in the dorsal interossei. In our series, we present shortenings without functional repercussion. Despite this, we cannot recommend it as the technique of choice in these fractures.

Attention must be paid to possible malrotation caused during threading, limiting the digital rotation during insertion. If it occurs, the screw should be slightly removed to correct it. A $10^{\circ}$ metacarpal rotation causes $2 \mathrm{~cm}$ of overlap on the fingertip. Therefore, it is essential to check the alignment. ${ }^{22}$

Regarding open fractures, and despite the fact that we have had no problems with infection associated with the implant, we cannot recommend it as the technique of choice, due to the possible associated risk of infection, which could lead to osteomyelitis and create a complicated situation for the patient.

From our point of view, one of the most significant problems we can find associated with the implant is its removal, either due to infection or rupture, especially if it has already osseointegrated, which can be an extremely difficult maneuver.

As discussed in the introduction, the present series of patients was treated by several surgeons with wide-ranging clinical experience. This could be seen as a weakness in our series, since the different experiences and skills of the surgeons could lead to mixed results. However, from our point of view, this demonstrates the strength of the technique, its reproducibility of execution and of the expected results, independently of the experience of the surgeon, if it is performed in a systematic and precise manner.

\section{Conclusion}

Our experience, in addition to that previously published, makes us recommend the use of cannulated screws as a versatile and effective option, which allows us to treat different types of fractures in a manner which is satisfactory to patients.

\section{References}

1 Karl JW, Olson PR, Rosenwasser MP. The epidemiology of upper extremity fractures in the United States, 2009. J Orthop Trauma 2015;29(08):e242-e244
2 Hsu LP, Schwartz EG, Kalainov DM, Chen F, Makowiec RL. Complications of K-wire fixation in procedures involving the hand and wrist. J Hand Surg Am 2011;36(04):610-616

3 Held M, Jordaan P, Laubscher M, Singer M, Solomons M. Conservative treatment of fractures of the proximal phalanx: an option even for unstable fracture patterns. Hand Surg 2013;18(02):229-234

4 Page SM, Stern PJ. Complications and range of motion following plate fixation of metacarpal and phalangeal fractures. J Hand Surg Am 1998;23(05):827-832

5 del Piñal F, Moraleda E, Rúas JS, de Piero GH, Cerezal L. Minimally invasive fixation of fractures of the phalanges and metacarpals with intramedullary cannulated headless compression screws. J Hand Surg Am 2015;40(04):692-700

6 Ruchelsman DE, Puri S, Feinberg-Zadek N, Leibman MI, Belsky MR. Clinical outcomes of limited-open retrograde intramedullary headless screw fixation of metacarpal fractures. J Hand Surg Am 2014;39(12):2390-2395

7 Aita MA, Mos PA, de Paula Cardoso Marques Leite G, Alves RS, Credídio MV, da Costa EF. Minimally invasive surgical treatment for unstable fractures of the proximal phalanx: intramedullary screw. Rev Bras Ortop 2015;51(01):16-23

8 Rivera Vegas MJ. Estefania Diez M.E., Martinez Nuñez P. Astorga Veganzones R. Use of Intramedullary Cannulated Headless Screws in the Treatment of Hand Fractures - An Anatomical Study on Long Fingers. Rev Iberam Cir Mano 2017;45:94-103

9 Rivera Vegas MJ. Martinez Nuñez P. Astorga Veganzones R. Approach to the Adequate Choice of the Intramedullary Screw for the Treatment of Hand Bone Fractures - Radiological Study in Metacarpals and Proximal and Medial Phalanges. Rev Iberam Cir Mano 2018;46:26-33

10 Botte MJ, Davis JL, Rose BA, et al. Complications of smooth pin fixation of fractures and dislocations in the hand and wrist. Clin Orthop Relat Res 1992;(276):194-201

11 Faruqui S, Stern PJ, Kiefhaber TR. Percutaneous pinning of fractures in the proximal third of the proximal phalanx: complications and outcomes. J Hand Surg Am 2012;37(07):1342-1348

12 Hornbach EE, Cohen MS. Closed reduction and percutaneous pinning of fractures of the proximal phalanx. J Hand Surg $[\mathrm{Br}]$ $2001 ; 26(01): 45-49$

13 Gajendran VK, Gajendran VK, Malone KJ. Management of complications with hand fractures. Hand Clin 2015;31(02):165-177

14 Fujitani R, Omokawa S, Shigematsu K, Tanaka Y. Comparison of the intramedullary nail and low-profile plate for unstable metacarpal neck fractures. J Orthop Sci 2012;17(04):450-456

15 Sammer DM, Husain T, Ramirez R. Selection of appropriate treatment options for hand fractures. Hand Clin 2013;29(04):501-505

16 Gaston RG, Chadderdon C. Phalangeal fractures: displaced/nondisplaced. Hand Clin 2012;28(03):395-401, x

17 Yamazaki H, Miyaoka S, Kato H. Attrition of the Extensor Tendon of the Index Finger Following an Avulsion Fracture of the Third Metacarpal. J Hand Surg Asian Pac Vol 2018;23(01):144-148

18 Doarn MC, Nydick JA, Williams BD, Garcia MJ. Retrograde headless intramedullary screw fixation for displaced fifth metacarpal neck and shaft fractures: short term results. Hand (N Y) 2015;10(02):314-318

19 Boulton CL, Salzler M, Mudgal CS. Intramedullary cannulated headless screw fixation of a comminuted subcapital metacarpal fracture: case report. J Hand Surg Am 2010;35(08):1260-1263

20 Shimizu T, Omokawa S, Akahane M, et al. Predictors of the postoperative range of finger motion for comminuted periarticular metacarpal and phalangeal fractures treated with a titanium plate. Injury 2012;43(06):940-945

21 Meunier MJ, Hentzen E, Ryan M, Shin AY, Lieber RL. Predicted effects of metacarpal shortening on interosseous muscle function. J Hand Surg Am 2004;29(04):689-693

22 Seitz WHJr, Froimson AI. Management of malunited fractures of the metacarpal and phalangeal shafts. Hand Clin 1988;4(03):529-536 